\title{
Rubeosis Iridis Resulting from Agenesis of the Internal Carotid Artery: A Case Report
}

\author{
Yuuji Gyotoku, Takahiro Kawaji ${ }^{*}$, Masaru Inatani, Mikiko Fukushima and Hidenobu Tanihara \\ Department of Ophthalmology and Visual Science, Graduate School of Medical Sciences, Kumamoto University, 1-1-1 \\ Honjo, Kumamoto 860-8556, Japan
}

\begin{abstract}
We report a case of rubeosis iridis resulting from agenesis of the internal carotid artery. Agenesis of the internal carotid artery is a rare congenital anomaly, and most patients do remain asymptomatic, but we should realize that this condition may lead to ocular ischemic changes, the result being rubeosis iridis.
\end{abstract}

Keywords: Rubeosis iridis, agenesis of the internal carotid artery, glaucoma, trabeculectomy.

\section{INTRODUCTION}

Agenesis of the internal carotid artery (ICA) is a rare congenital anomaly and is usually asymptomatic because of the abundant collateral supply from other vessels [1]. Here, we report a case of rubeosis iridis resulting from agenesis of the ICA.

\section{CASE}

A 47-year-old woman presented with blurred vision in her left eye. An ophthalmic examination showed visual acuity to be $20 / 20$ in the right eye and $20 / 25$ in the left eye. Intraocular pressure (IOP) measured $10 \mathrm{mmHg}$ in the right eye and $32 \mathrm{mmHg}$ in the left eye. Slit-lamp examination revealed

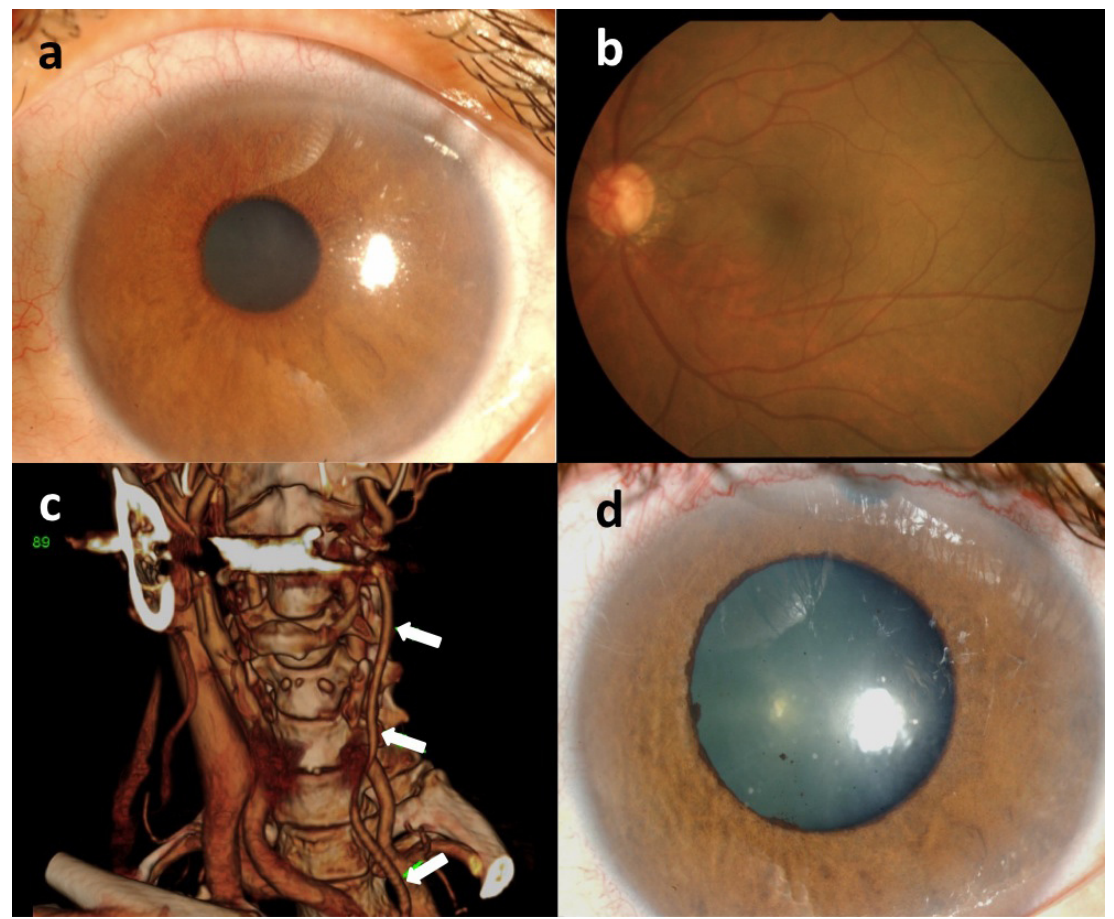

Fig. (1). (a) Slit-lamp examination showed corneal edema and rubeosis iridis in the left eye. (b) Fundus examination showed glaucomatous changes of the optic disc and almost normal retinal vessels. (c) Three-dimensional computed tomography angiography revealed absence of the left internal carotid artery and thinned common carotid artery (arrows). (d) A few days after the trabeculectomy, rubeosis iridis disappeared.

*Address correspondence to this author at the Department of Ophthalmology and Visual Science, Graduate School of Medical Sciences, Kumamoto University, 1-1-1 Honjo, Kumamoto 860-8556, Japan; Tel: +81-96-3735247; Fax: +81-96-373-5249; E-mail: kawag@white.plala.or.jp corneal edema and rubeosis iridis in the left eye (Fig. 1a). Gonioscopy demonstrated peripheral anterior synechia on the upper nasal side in the left eye, with unclear neovascularisation because of corneal edema. The optic disc in the left 
eye also had glaucomatous changes, and visual field testing showed glaucomatous defects. Moreover, the artery on the optic disc had pulsation with relatively mild IOP elevation. Retinal vessels seemed to be almost normal (Fig. 1b), but fluorescein angiography indicated the following findings: arm-retinal time was normal in both eyes; a prolonged retinal arteriovenous transit time (10 seconds in the right eye and 25 seconds in the left eye); slight retinal capillary nonperfusion in the left eye. The right eye had no abnormality of any kind. General physical and neurologic examinations were unremarkable. However, carotid Doppler ultrasound study showed the left internal carotid artery (ICA) was neither visualized nor detected. Magnetic resonance angiography showed a left dilated vertebral artery, thinned common carotid artery, and absence of ICA. Three-dimensional computed tomography angiography revealed the absence of the left ICA (Fig. 1c) and carotid canals, which confirmed agenesis of the left ICA, and supply of the left middle cerebral artery by the left posterior communicating artery. Despite use of antiglaucoma medications, IOP was higher than 30 $\mathrm{mmHg}$. Trabeculectomy with use of mitomycin $\mathrm{C}$ was performed in November 2005.

After trabeculectomy with no complication, IOP decreased, rubeosis iridis disappeared (Fig. 1d), and the retinal arteriovenous transit time improved to within normal limits. IOP was well controlled for 2.5 years.

\section{DISCUSSION}

Agenesis of the ICA is a rare congenital anomaly, which occurs in less than $0.01 \%$ of the population [1]. The mechanism of formation of this anomaly is not completely clear.
Likely possibilities include secondary regression after a normal initial development and arrested development at a certain early embryonic stage. ICA agenesis is usually asymptomatic because of the abundant collateral supply from the contralateral ICA and basilar systems [2]. However, the new vessels are threatened by rupture with subarachnoid or meningeal hemorrhage and by ischemia [3]. Only one case, anterior ischemic optic neuropathy, has been reported as an ocular symptom of ICA agenesis [4].

That this case manifested rubeosis iridis is of interest. This patient with ICA agenesis was asymptomatic, even though blood pressure of the retinal vessel may have been mildly lower. We believe that this mildly lower blood pressure of retinal arteries, which resulted from ICA agenesis, combined with IOP elevation may have led to ischemia, the result being rubeosis iridis. Agenesis of the ICA is rare, and most patients do remain asymptomatic, but we should realize that this condition may lead to ocular ischemic changes.

\section{REFERENCES}

[1] Afifi AK, Godersky JC, Menezes A, Smoker WR, Bell WE, Jacoby CG. Cerebral hemiatrophy, hypoplasia of internal carotid artery, and intracranial aneurysm. A rare association occurring in an infant. Arch Neurol 1987; 44: 232-5.

[2] Quint DJ, Silbergleit R, Young WC. Absence of the carotid canals at skull base CT. Radiology 1992; 182: 477-81.

[3] Servo A. Agenesis of the left internal carotid artery associated with an aneurysm on the right carotid syphon. Case report. J Neurosurg 1977; 46: 677-80.

[4] Horowitz J, Melamud A, Sela L, Hod Y, Geyer O. Internal carotid artery hypoplasia presenting as anterior ischemic optic neuropathy. Am J Ophthalmol 2001; 131: 673-4. 